\title{
Effects of body weight-supported treadmill training combined with ball-kicking on balance and gait of subacute stroke patients
}

\author{
Juchul Cho ${ }^{a}$, Eunsang Lee ${ }^{b, c}$, Seungwon Lee ${ }^{d}$ \\ ${ }^{a}$ Rehabilitation Team, Konyang University Hospital, Daejeon, Republic of Korea \\ ${ }^{b}$ Department of Physical Therapy, The Graduate School of Sahmyook University, Seoul, Republic of Korea \\ 'Department of Physical Therapy, Gwangju Health University, Gwangju, Republic of Korea \\ ${ }^{\mathrm{d} D e p a r t m e n t}$ of Physical Therapy, Sahmyook University, Seoul, Republic of Korea
}

Objective: This study focused on subacute stroke patients who were asked to kick a ball while walking on a treadmill. The aim of the study was to determine the effect of a body weight-supported treadmill training (BWSTT) combined with ball-kicking on muscle strength, balance, and gait.

Design: Single blind, randomized controlled trial.

Methods: Twenty stroke patients who volunteered to participate in this study were randomly assigned to either the BWSTT combined with ball-kicking (BWSTT-BK; 10 participants) group or the BWSTT group (10 participants). Participants in the BWSTTBK group performed treadmill walking combined with simultaneous ball-kicking for 30 minutes daily for 5 weeks. Participants from the BWSTT group performed only treadmill walking. The muscular strength, balance, and gait ability were measured before and after the 5-week training. To assess for muscular strength, a digital muscle tester was used to measure hip flexor, knee extensor, and dorsiflexor strength. To assess for balance, the Berg Balance Scale (BBS) and Timed Up and Go Test (TUG) was used. To assess for gait, the 10 meter walk test (10MWT) and Functional Gait Assessment (FGA) was used.

Results: The BWSTT-BK group showed significantly improved muscular strength, balance, and gait according to BBS, TUG, 10MWT, FGA, and digital muscle testing scores compared to the BWSTT group $(p<0.05)$. In addition, within-group comparison showed significant improvement in all variables $(p<0.05)$.

Conclusions: These findings suggest that BWSTT-BK results in more favourable outcomes for stroke patients. Therefore, BWSTT-BK may be useful for the recovery of gait ability of stroke patients.

Key Words: Gait, Postural balance, Stroke, Weight-bearing

\section{Introduction}

Stroke is a condition in which function in parts of the brain is affected due to infarction or hemorrhage of the blood vessels, leading to significant brain dysfunction [1]. Stroke patients exhibit abnormal gait patterns and there is a noticeable decrease (1.1-1.5 m/s) in their walking speed in comparison to normal walking speed [2]. The ability to properly respond to various environmental stimuli and perform motor tasks also decreases because of a decline in co-ordination ability
[3]; there is a difference in bilateral stride length due to muscular weakness of the paretic lower extremity [4], asymmetrical posture, and balance and gait disturbance depending on the non-paretic lower extremity [5]. These disabilities limit daily activities and increase the risk of falling after discharge from hospital [6].

When tasks are performed simultaneously rather than independently, balance capability can be lost due to muscular weakness and loss of concentration [7]. Daily activities involve complex tasks, and the risk of falls increases due to the

Received: 11 November, 2015 Revised: 18 December, 2015 Accepted: 18 December, 2015

Corresponding author: Seungwon Lee

Department of Physical Therapy, Sahmyook University, 815 Hwarang-ro, Nowon-gu, Seoul 01795, Republic of Korea

Tel: 82-2-3399-1637 Fax: 82-2-3399-1639 E-mail: swlee@syu.ac.kr

(c) This is an Open-Access article distributed under the terms of the Creative Commons Attribution Non-Commercial License (http://creativecommons.org/licens es/by-nc/4.0) which permits unrestricted non-commercial use, distribution, and reproduction in any medium, provided the original work is properly cited.

Copyright @ 2015 Korean Academy of Physical Therapy Rehabilitation Science 
difficultly in performing simultaneous tasks while walking [8]. Dual-task training, where patients perform two or more tasks simultaneously, requires discipline [9]. Stroke patients with cognitive impairment and movement disorders need repeated dual-task training in order to carry out normal daily activities and prevent falls after discharge from hospital. Stable walking requires both balance and successful secondary task performance [10]. Focusing training on the muscle strength of the lower extremities can be an effective way to improve balance, walking speed, and walking distance [11]. This training also helps build confidence in performing daily activities, thus helping stroke patients connect with their community and also save on medical expenses [12].

Body weight-supported treadmill training (BWSTT) is widely used for balance and walking training. BWSTT has allowed researchers to further investigate the motor control of walking and uses a body weight support belt (under the safety and protection of therapists) [13] and allows manipulation of walking environments by allowing the adjustment of belt speed and gradient [14]. Therapists can also provide specific feedback, and the gait correction and functional assessment during BWSTT can help in the development of an effective exercise strategy by focusing on muscles needed for walking in a patient-specific manner [15]. Patterson et al. [16] reported that, following treadmill training, non-paretic stride length increased and there were improvements in both step count and gait speed. Lau and Mak [17] reported that stride length and gait speed improved after speed-dependent treadmill training. Lathan et al. [18] also reported that peak hip and knee flexion, stride length, and gait speed improved after pressure-controlled treadmill training.

Walking training programs that include components of daily life are required in clinical practice to allow stroke patients to return early and successfully to the community. Although there is rising interest in the community activities and gait task trainings of stroke patients, research on the composition and effect of the dual-task training program is lacking. Therefore, this study focused on subacute stroke patients who were asked to kick a ball while walking on a treadmill. The aim of the study was to determine the effect of this dual-task training on muscle strength, balance, and gait speed.

\section{Methods}

\section{Subjects}

The study was conducted with 20 patients selected from a total of 25 stroke patients hospitalized at $\mathrm{K}$ University Hospital in Daejeon, Republic of Korea. All patients were receiving physical therapy, agreed to participate in the study, and satisfied the study conditions. The remaining 5 patients were discharged from hospital or were not in a condition to participate. The inclusion criteria for this study were duration of 7 days since the initial stroke, ability to walk more than 10 minutes on the treadmill, no visual and auditory problems, a mini-mental state examination score of greater than 24, no orthopedic diseases in the lower limbs, and no cardiovascular disease that could limit gait training. The general characteristics of the study participants are shown in Table 1. There were no significant differences between the two groups with respect to gender, age, height, weight, days since stroke, type of stroke, and paretic part.

\section{Procedure}

The treatment groups were assigned randomly by allowing participants to select one of two cards (experimental and control cards) placed in a box. Participants were not informed of the research hypothesis, and the evaluator was blinded to the assignment of the treatment groups. Participants in both groups performed treadmill (Biodex Medical Systems Inc., New York, NY, USA) walking training for 30 minutes, every day for 5 weeks, in addition to their basic therapy exercise schedule. The assessments were conducted at the start and after 5 weeks of the exercise training in the two groups. The gait training was performed concurrently in order to prevent participants from falling. Participants rested when they felt tired during training.

Table 1. Demographic and anthropological characteristics of the subjects

\begin{tabular}{lccr}
\hline \multicolumn{1}{c}{ Characteristic } & $\begin{array}{c}\text { BWSTT-BK } \\
(\mathrm{n}=10)\end{array}$ & $\begin{array}{c}\text { BWSTT } \\
(\mathrm{n}=10)\end{array}$ & $\mathrm{t} / \chi^{2}$ \\
\hline Age (yr) & $63.70(8.33)$ & $57.50(9.01)$ & -1.60 \\
Sex (male/female) & $7 / 3$ & $8 / 2$ & 0.27 \\
Height (cm) & $162.6(9.08)$ & $167.40(4.70)$ & 1.49 \\
Weight (kg) & $60.6(9.43)$ & $64.40(9.70)$ & 0.89 \\
Time after stroke (d) & $48.90(45.74)$ & $57.70(33.72)$ & 0.49 \\
$\begin{array}{c}\text { Stroke type (hemor- } \\
\text { rhage/infarction) }\end{array}$ & $5 / 5$ & $5 / 5$ & 0.00 \\
$\begin{array}{c}\text { Hemiparetic side } \\
\text { (right/left) }\end{array}$ & $6 / 4$ & $2 / 8$ & 3.33 \\
\hline
\end{tabular}

Values are presented as mean (SD) or number only. BWSTT: body weight-supported treadmill training, BWSTT-BK: BWSTT combined with ball-kicking. 


\section{Intervention}

\section{BWSTT combined with kicking ball}

BWSTT combined with ball-kicking (BWSTT-BK) was performed by initially attaching a fishing line around an orange ball, placed $30 \mathrm{~cm}$ off the ground to make the sound from the outside pressure and to be distinguished from the floor so as to enhance an auditory effect (Figure 1). The treadmill gait training began at a slow pace of $0.3 \mathrm{~km} / \mathrm{h}$, and was gradually increased by $0.1 \mathrm{~km} / \mathrm{h}$ until the participants felt comfortable. Participants in the BWSTT-BK group were required to kick a ball using the paretic leg in order to improve strength and balance ability. Initially, $30 \%$ of the participant's weight was supported on the treadmill (measured by a digital scale) and at the stance phase of walking, the rate decreased to $0 \%$ leading to increasing gait speed due to sufficient weight bearing. The same procedure was followed by the BWSTT group, except for kicking of a ball.

\section{Measurements}

Results were obtained using a digital muscle tester (J-TechTM Commander-powerTrack II MMT; JTECH Medical, Midvale, UT, USA) and four types of balance and gait tests (Berg Balance Scale, BBS, timed up and go [TUG] test, 10 $\mathrm{m}$ walk test [10MWT], and functional gait assessment [FGA]).

Digital muscle testing (DMT) was used in the sitting position in order to measure muscle strength in the hip flexor, knee extensor, and ankle dorsiflexor. The lower extremity muscle strength of subjects was measured in the sitting position. The proximal part of the knee joint, superior part of the ankle joint, and the medial dorsal aspect were put on the force plate and maximal isometric contraction was forced to occur during mid-range movement of each joint. The average of two values was obtained by measuring the maximum pressure at the moment that the contraction was maintained [19].

BBS and TUG scores were used as criteria to evaluate the functional balance performance and the patient's falling risk. The higher the BBS score, the lower the need for help for the patient. Static and dynamic balance ability were rated against 14 criteria using a 5-point scale of measurement, from 0 to 4 points, with a maximal score of 56. Inter-rater reliability is $\mathrm{r}=0.98$ and intra-rater reliability is $\mathrm{r}=0.99[20,21]$. TUG evaluates both functional mobility and balance ability and the results are reported as the time required for a participant in the sitting position to stand up from an armchair at the starting signal, travel past a certain point ( $3 \mathrm{~m}$ ), and sit on a chair again. Inter-rater reliability is $\mathrm{r}=0.98$ and intra-rater reliability is $\mathrm{r}=0.99$ [22].

10MWT was used to evaluate the gait ability of stroke patients. Patients were required to walk through a $12 \mathrm{~m}$ walking passage in a straight line, and the time required to travel the $10 \mathrm{~m}$ passage was measured (the extra $2 \mathrm{~m}$ allowed for acceleration and deceleration at the start and endpoint of the passage). For measuring walking time, the reliability of the 10MWT is $r=0.87$ [23]. FGA was also used to evaluate the dynamic gait index. Ten criteria were measured using a 4-point scale, ranging from 0 point to 3 points, with a maximum score of 30 . Inter-rater reliability is $r=0.94$ and intra-rater reliability is $\mathrm{r}=0.97$ [24].

\section{Data analysis}

The statistical analysis of all measurement values was

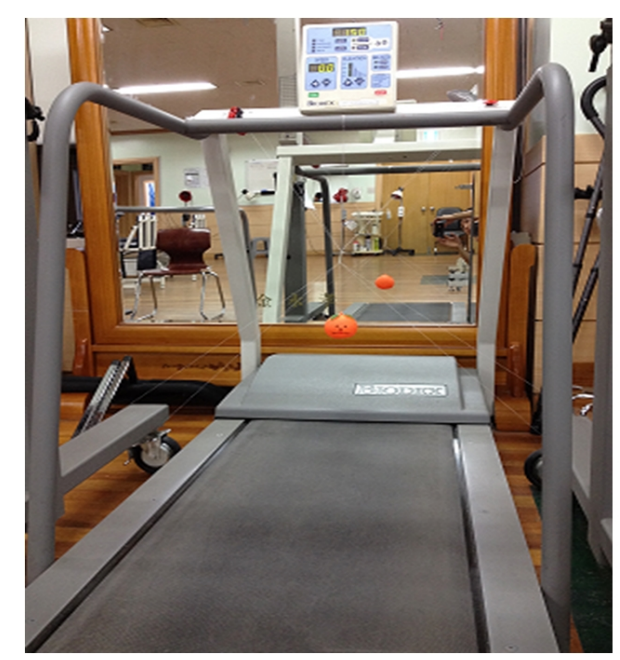

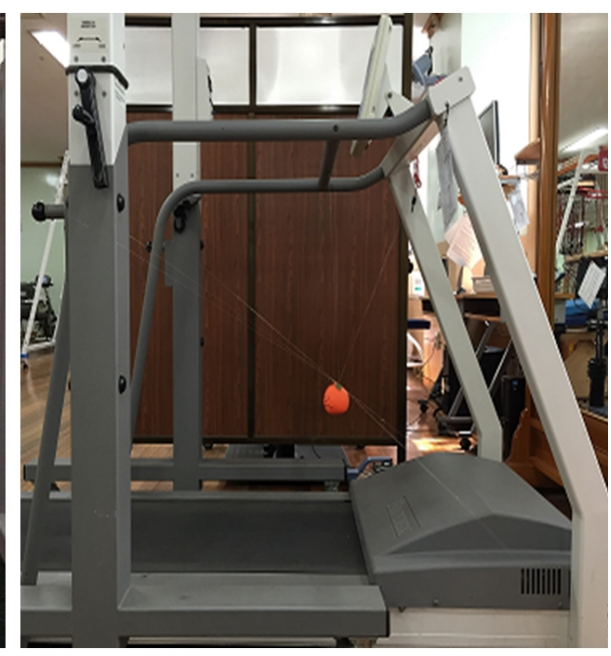

Figure 1. Body weight-supported treadmill training combined with ball-kicking. 
Table 2. Comparison of muscular strength within groups and between groups

$(\mathrm{N}=20)$

\begin{tabular}{|c|c|c|c|c|c|c|}
\hline \multirow{2}{*}{ Variable } & \multicolumn{2}{|c|}{ BWSTT-BK $(n=10)$} & \multirow{2}{*}{$\begin{array}{l}\text { Change } \\
\text { value }\end{array}$} & \multicolumn{2}{|c|}{ BWSTT $(\mathrm{n}=10)$} & \multirow{2}{*}{$\begin{array}{c}\text { Change } \\
\text { value }\end{array}$} \\
\hline & Pre-test & Post-test & & Pre-test & Post-test & \\
\hline $\mathrm{HF}(\mathrm{N})$ & $95.00(32.66)$ & $121.30(3,0.35)^{\mathrm{a}}$ & $26.30(14.00)$ & $95.20(33.16)$ & $116.70(32.05)^{\mathrm{a}}$ & $21.50(17.19)$ \\
\hline $\mathrm{KE}(\mathrm{N})$ & $100.20(28.93)$ & $140.10(23.72)^{\mathrm{a}}$ & $39.90(15.20)$ & $101.60(35.18)$ & $125.30(37.98)^{\mathrm{a}}$ & $23.70(14.83)^{b}$ \\
\hline $\mathrm{AD}(\mathrm{N})$ & $104.60(28.88)$ & $148.50(25.94)^{\mathrm{a}}$ & $43.90(13.07)$ & $107.40(38.82)$ & $134.10(40.27)^{\mathrm{a}}$ & $26.70(17.51)^{\mathrm{b}}$ \\
\hline
\end{tabular}

Values are presented as mean (SD).

HF: hip flexor, KE: knee extensor, AD: ankle dorsiflexor, BWSTT: body weight-supported treadmill training, BWSTT-BK: BWSTT combined with ball-kicking.

${ }^{a}$ Significant difference between pre and post training within the group $(p<0.05)$. ${ }^{\mathrm{b}}$ Significant difference between the change values among the groups $(p<0.05)$.

Table 3. Comparison of the balance and gait variables within groups and between groups

$(\mathrm{N}=20)$

\begin{tabular}{|c|c|c|c|c|c|c|}
\hline & \multicolumn{2}{|c|}{ BWSTT-BK $(\mathrm{n}=10)$} & \multirow{2}{*}{$\begin{array}{c}\text { Change } \\
\text { value }\end{array}$} & \multicolumn{2}{|c|}{ BWSTT $(n=10)$} & \multirow{2}{*}{$\begin{array}{l}\text { Change } \\
\text { value }\end{array}$} \\
\hline & Pre-test & Post-test & & Pre-test & Post-test & \\
\hline BBS (score) & $42.40(8.69)$ & $51.50(4.38)^{\mathrm{a}}$ & $9.10(6.49)$ & $46.00(6.77)$ & $49.20(3.74)^{\mathrm{a}}$ & $3.20(3.88)^{\mathrm{b}}$ \\
\hline TUG (sec) & $19.39(7.13)$ & $10.74(2.52)^{\mathrm{a}}$ & $-8.65(5.37)$ & $16.87(7.87)$ & $13.50(5.11)^{\mathrm{a}}$ & $-3.37(4.63)^{b}$ \\
\hline 10MWT (sec) & $17.20(7.15)$ & $9.19(2.05)^{\mathrm{a}}$ & $-8.01(5.70)$ & $13.52(6.06)$ & $10.50(3.22)^{\mathrm{a}}$ & $-3.02(4.04)^{b}$ \\
\hline FGA (score) & $16.10(6.89)$ & $23.60(3.06)^{\mathrm{a}}$ & $7.50(4.28)$ & $15.70(4.88)$ & $19.80(4.59)^{\mathrm{a}}$ & $-4.10(2.13)^{b}$ \\
\hline
\end{tabular}

Values are presented as mean (SD).

BBS: Berg Balance Scale, TUG: timed up and go, 10MWT: $10 \mathrm{~m}$ walk test, FGA: functional gait assessment, BWSTT: body weight-supported treadmill training, BWSTT-BK: BWSTT combined with ball-kicking.

${ }^{a}$ Significant difference between pre and post training within the group $(p<0.05)$. ${ }^{\mathrm{b}}$ Significant difference between the change values among the groups $(p<0.05)$.

performed using SPSS ver. 18.0 (SPSS Inc., Chicago, IL, USA). The Kolmogorov-Smirnov verification was used to confirm the normality of data, which were found to be normally distributed. The general characteristics and the initial test results of participants were analyzed by the chi-square test and independent t-test to test for homogeneity. Paired $\mathrm{t}$-tests were performed to analyze differences in balance and gait ability within each group before and after intervention. Independent t-tests were used to compare the differences between both groups. The statistical significance level was set at $\alpha=0.05$.

\section{Results}

\section{Comparison of before-after measures of BWSTT-BK patients}

There was a statistically significant improvement in DMT (hip flexor, knee extensor, ankle dorsiflexor), BBS, TUG, 10MWT, and FGA results compared to those before and after gait training in BWSTT-BK patients $(p<0.05)$.

\section{Comparison of before-after measures of BWSTT patients}

There was a statistically significant improvement in DMT (hip flexor, knee extensor, ankle dorsiflexor), BBS, TUG, 10MWT, and FGA results compared to those before and after gait training in BWSTT patients $(p<0.05)$.

\section{Comparison of measures between BWSTT-BK and BWSTT patients}

There was a statistically significant difference in DMT (knee extensor, ankle dorsiflexor), BBS, TUG, 10MWT, and FGA results between BWSTT-BK and BWSTT patients before and after gait training $(p<0.05)$. There was no significant difference in DMT results for the hip flexor (Tables $2,3)$.

\section{Discussion}

This study focused on subacute stroke patients who performed the dual task of walking and kicking a ball. This methodology allowed the elucidation of muscle strength, analysis of balance capability, and identification of the func- 
tional effect on walking of dual-task training. In this study, we achieved dual-task training by asking participants to kick a ball whilst walking. The result of this study indicated that there was a functional benefit in patients in both the BWSTT-BK and BWSTT groups. Furthermore, BWSTTBK was more effective than BWSTT (Tables 2, 3).

The main goal of training is to restore stable balance and allow recovery of functional walking ability in stroke patients as it is one of the main factors that influences quality of life. A recent study of subacute stroke patients reported that there was a change in muscle structure after gait training on a treadmill [25]. Specifically, the results showed larger pennation angle and muscle thickness of the tibialis anterior and longer fascicle length of the medial gastrocnemius after the training. Similarly, this study also indicated that after gait training on the treadmill, there was a significant effect (both within-group and between-group) on muscle strength in the knee extensor and ankle dorsiflexor when analyzed using DMT. However, no significant difference was identified in the hip flexors following gait training. The lack of difference between groups in hip flexor strength may be due to the limited length of the hamstring muscle, while the majority of the work is performed by the simultaneous activity of the knee extensor and ankle dorsiflexor.

BWSTT is now largely performed to enhance the balance and gait speed of stroke patients in clinical practice [26]. There are, however, conflicting views about the clinical relevance of BWSTT. Middleton et al. [27] reported that there was a significant difference in balance and gait speed between stroke patients who underwent BWSTT and those who underwent overground gait training (OGT), but there was no difference in between group comparison. CombsMiller et al. [28] reported a significant improvement of selfselected walking speed in the OGT group compared to that in the BWSTT group. Furthermore, Bonnyaud et al. [29] reported that the times recorded for the TUG test decreased in both the BWSTT and OGT groups. In the current study, there was a significant improvement in BBS, TUG, 10MWT, and FGA scores with the addition of the task of kicking a ball to an existing 5-week BWSTT. It was indicated that there was a difference of recovery time. This was because the time of onset of subacute or chronic stroke subjects were different. This study, using dual-task training, produced distinctly different results compared with previous studies using single task training. Previous studies have indicated that a task-orientated intervention as a complex training method improved both walking distance and walking speed of stroke patients [30]. The observed walking speed improvements after dual-task training were greater than after single-task training when assessed following 4 weeks of balance training in the elderly with disequilibrium [31]. In addition, there was a significant effect on walking speed, average stride length, and cadence after dual-task training [32]. It is thought that dual-task training is a more useful intervention, as fast walking speed can lead to an enhanced risk of falling due to suddenly unexpected situations when stroke patients walk independently in the community. This study also identified that BWSTT-BK was a more effective intervention, similar to previous studies.

There are some limitations to this study. It is difficult to generalize the results of this study to all stroke patients. This is partially due to the difficulty of selecting participants and the small numbers of available participants due to their discharge from hospital or unsuitable condition. Moreover, this study did not measure the degree of fatigue in participants that occurred as a result of repetitive training. Finally, it is not clear how long the training effect lasted as no follow-up was performed. Therefore, future studies should be performed overcome these limitations. We suggest that BWSTT-BK should be considered an important tool in clinical practice when gait training programs are planned.

\section{Conflict of Interest}

The authors declared no potential conflicts of interest with respect to the authorship and/or publication of this article.

\section{References}

1. Prange GB, Jannink MJ, Groothuis-Oudshoorn CG, Hermens HJ, Ijzerman MJ. Systematic review of the effect of robot-aided therapy on recovery of the hemiparetic arm after stroke. J Rehabil Res Dev 2006;43:171-84.

2. Pohl M, Mehrholz J, Ritschel C, Rückriem S. Speed-dependent treadmill training in ambulatory hemiparetic stroke patients: a randomized controlled trial. Stroke 2002;33:553-8.

3. Roerdink M, Lamoth CJ, Kwakkel G, van Wieringen PC, Beek PJ. Gait coordination after stroke: benefits of acoustically paced treadmill walking. Phys Ther 2007;87:1009-22.

4. Mauritz KH. Gait training in hemiplegia. Eur J Neurol 2002;9 Suppl 1:23-9.

5. Liepert J, Bauder H, Wolfgang HR, Miltner WH, Taub E, Weiller C. Treatment-induced cortical reorganization after stroke in humans. Stroke 2000;31:1210-6.

6. Geurts AC, de Haart M, van Nes IJ, Duysens J. A review of standing balance recovery from stroke. Gait Posture 2005;22:267-81. 
7. Brauer SG, Woollacott M, Shumway-Cook A. The influence of a concurrent cognitive task on the compensatory stepping response to a perturbation in balance-impaired and healthy elders. Gait Posture 2002;15:83-93.

8. Verghese J, Buschke H, Viola L, Katz M, Hall C, Kuslansky G, et al. Validity of divided attention tasks in predicting falls in older individuals: a preliminary study. J Am Geriatr Soc 2002;50: 1572-6.

9. Pellecchia GL. Dual-task training reduces impact of cognitive task on postural sway. J Mot Behav 2005;37:239-46.

10. McCulloch KL, Buxton E, Hackney J, Lowers S. Balance, attention, and dual-task performance during walking after brain injury: associations with falls history. J Head Trauma Rehabil 2010;25:155-63.

11. Al-Jarrah M, Shaheen S, Harries N, Kissani N, Molteni F, Bar Haim S; MESF Project. Individualized treadmill and strength training for chronic stroke rehabilitation: effects of imbalance. Top Stroke Rehabil. 2014;21 Suppl 1:S25-32.

12. Dean CM, Richards CL, Malouin F. Task-related circuit training improves performance of locomotor tasks in chronic stroke: a randomized, controlled pilot trial. Arch Phys Med Rehabil 2000; 81:409-17.

13. Sullivan KJ, Knowlton BJ, Dobkin BH. Step training with body weight support: effect of treadmill speed and practice paradigms on poststroke locomotor recovery. Arch Phys Med Rehabil 2002;83:683-91.

14. Ada L, Dean CM, Hall JM, Bampton J, Crompton S. A treadmill and overground walking program improves walking in persons residing in the community after stroke: a placebo-controlled, randomized trial. Arch Phys Med Rehabil 2003;84:1486-91.

15. Miller EW, Quinn ME, Seddon PG. Body weight support treadmill and overground ambulation training for two patients with chronic disability secondary to stroke. Phys Ther 2002;82:53-61.

16. Patterson SL, Rodgers MM, Macko RF, Forrester LW. Effect of treadmill exercise training on spatial and temporal gait parameters in subjects with chronic stroke: a preliminary report. J Rehabil Res Dev 2008;45:221-8.

17. Lau KW, Mak MK. Speed-dependent treadmill training is effective to improve gait and balance performance in patients with sub-acute stroke. J Rehabil Med 2011;43:709-13.

18. Lathan C, Myler A, Bagwell J, Powers CM, Fisher BE. Pressurecontrolled treadmill training in chronic stroke: a case study with AlterG. J Neurol Phys Ther 2015;39:127-33.

19. Krebs DE, Scarborough DM, McGibbon CA. Functional vs. strength training in disabled elderly outpatients. Am J Phys Med Rehabil 2007;86:93-103.

20. Beninato M, Portney LG, Sullivan PE. Using the International Classification of Functioning, Disability and Health as a frame- work to examine the association between falls and clinical assessment tools in people with stroke. Phys Ther 2009;89:816-25.

21. Kim JH. A study on the correlation between static, dynamic standing balance symmetry and walking function in stroke. $\mathbf{J}$ Korean Soc Phys Ther 2012;24:73-81.

22. Podsiadlo D, Richardson S. The timed "Up \& Go": a test of basic functional mobility for frail elderly persons. J Am Geriatr Soc 1991;39:142-8

23. Green J, Forster A, Young J. Reliability of gait speed measured by a timed walking test in patients one year after stroke. Clin Rehabil 2002;16:306-14.

24. Thieme H, Ritschel C, Zange C. Reliability and validity of the functional gait assessment (German version) in subacute stroke patients. Arch Phys Med Rehabil 2009;90:1565-70.

25. Liu P, Wang Y, Hu H, Mao Y, Huang D, Li L. Change of muscle architecture following body weight support treadmill training for persons after subacute stroke: evidence from ultrasonography. Biomed Res Int 2014;2014:270676.

26. Ada L, Dean CM, Morris ME, Simpson JM, Katrak P. Randomized trial of treadmill walking with body weight support to establish walking in subacute stroke: the MOBILISE trial. Stroke 2010;41:1237-42.

27. Middleton A, Merlo-Rains A, Peters DM, Greene JV, Blanck EL, Moran R, et al. Body weight-supported treadmill training is no better than overground training for individuals with chronic stroke: a randomized controlled trial. Top Stroke Rehabil 2014; 21:462-76.

28. Combs-Miller SA, Kalpathi Parameswaran A, Colburn D, Ertel T, Harmeyer A, Tucker L, et al. Body weight-supported treadmill training vs. overground walking training for persons with chronic stroke: a pilot randomized controlled trial. Clin Rehabil 2014; 28:873-84.

29. Bonnyaud C, Zory R, Robertson J, Bensmail D, Vuillerme N, Roche N. Effect of an overground training session versus a treadmill training session on timed up and go in hemiparetic patients. Top Stroke Rehabil 2014;21:477-83.

30. Salbach NM, Mayo NE, Wood-Dauphinee S, Hanley JA, Richards CL, Côté R. A task-orientated intervention enhances walking distance and speed in the first year post stroke: a randomized controlled trial. Clin Rehabil 2004;18:509-19.

31. Silsupadol P, Shumway-Cook A, Lugade V, van Donkelaar P, Chou LS, Mayr U, et al. Effects of single-task versus dual-task training on balance performance in older adults: a double-blind, randomized controlled trial. Arch Phys Med Rehabil 2009;90: 381-7.

32. Plummer-D'Amato P, Altmann LJ, Saracino D, Fox E, Behrman $\mathrm{AL}$, Marsiske M. Interactions between cognitive tasks and gait after stroke: a dual task study. Gait Posture 2008;27:683-8. 